\title{
EFFECTS OF OCEAN TIDE MODELS ON GNSS-ESTIMATED ZTD AND PWV IN TURKEY
}

\author{
Gokhan Gurbuz*, Shuanggen Jin, Cetin Mekik \\ Department of Geomatics Engineering, Bulent Ecevit University, Zonguldak 67100, Turkey \\ (gokhanngurbuz@gmail.com, sgjin@shao.ac.cn, cmekik@ hotmail.com)
}

\section{SMPR2015}

KEY WORDS: Precipitable Water Vapour, Ocean Tide Models, GNSS, Zenith Tropospheric Delay (ZTD)

\begin{abstract}
:
Global Navigation Satellite System (GNSS) observations can precisely estimate the total zenith tropospheric delay (ZTD) and precipitable water vapour (PWV) for weather prediction and atmospheric research as a continuous and all-weather technique. However, apart from GNSS technique itself, estimations of ZTD and PWV are subject to effects of geophysical models with large uncertainties, particularly imprecise ocean tide models in Turkey. In this paper, GNSS data from Jan. $1^{\text {st }}$ to Dec. $31^{\text {st }}$ of 2014 are processed at 4 co-located GNSS stations (GISM, DIYB, GANM, and ADAN) with radiosonde from Turkish Met-Office along with several nearby IGS stations. The GAMIT/GLOBK software has been used to process GNSS data of 30-second sample using the Vienna Mapping Function and $10^{\circ}$ elevation cut-off angle. Also tidal and non-tidal atmospheric pressure loadings (ATML) at the observation level are also applied in GAMIT/GLOBK. Several widely used ocean tide models are used to evaluate their effects on GNSS-estimated ZTD and PWV estimation, such as IERS recommended FES2004, NAO99b from a barotropic hydrodynamic model, CSR4.0 obtained from TOPEX/Poseidon altimetry with the model FES94.1 as the reference model and GOT00 which is again long wavelength adjustments of FES94.1 using TOPEX/Poseidon data at 0.5 by 0.5 degree grid. The ZTD and PWV computed from radiosonde profile observations are regarded as reference values for the comparison and validation. In the processing phase, five different strategies are taken without ocean tide model and with four aforementioned ocean tide models, respectively, which are used to evaluate ocean tide models effects on GNSS-estimated ZTD and PWV estimation through comparing with co-located Radiosonde. Results showed that ocean tide models have greatly affected the estimation of the ZTD in centimeter level and thus the precipitable water vapour in millimeter level, respectively at stations near coasts. The ocean tide model FES2004 that is the product of assimilation of the altimetric data of ERS2, TOPEX/POSEIDON and the data of a global tide gauge network, gave the most accurate results when compared to radiosonde with $\pm 1.99 \mathrm{~mm}$ in PWV at stations near coastline. While other ocean tides models agree each other at millimeter level in PWV. However, at inland GNSS stations, ocean tide models have less effects on GNSSestimated ZTD and PWV, e.g., with $\pm 1.0 \mathrm{~mm}$ in ZTD and $\pm 0.1 \mathrm{~mm}$ in PWV.
\end{abstract}

\section{INTRODUCTION}

In GNSS meteorology, the total zenith tropospheric delay (ZTD) is an essential parameter, which can be converted into the water vapour. The tropospheric delay is the difference of the optical and geometric path in the atmosphere between the satellite and the receiver over the station. ZTD can be separated into two components: the dry zenith delay (ZHD) and the zenith wet delay (ZWD). The first one depends on the atmospheric pressure, which can be computed with the pressure value of the station directly and accurately, and the second one is computed by subtracting ZHD from ZTD. Then the ZWD is converted to the precipitable water vapour (PWV). Computation of precipitable water vapour from GNSS observation requires an estimation of zenith tropospheric delay of GNSS signal while it propagates through atmosphere. Apart from other error sources like the pressure, temperature or ZTD at the computation of PWV, ocean tide effects are one of errors (Dach and Dietrich, 2000), especially if the GNSS station is near ocean.

Accurate models of ocean loading are important for precise geodetic positioning, in particular for sub-daily positions (Baker et al., 1995), and for the determination of polar motion and UT1 parameters (Scherneck and Haas, 1999). In addition, because of the potential use of GNSS-estimated tropospheric delays for meteorological and climatological applications (e.g. Bevis et al., 1992; Duan et al., 1996), ocean loading must be accurately modelled in order to provide accurate tropospheric delay estimates that meet the accuracy requirements imposed by these new applications (Dach and Dietrich, 2000; Dragert et al., 2000). Since the GNSS site heights and the ZTD are strongly correlated, the ocean tide effects must be carefully modelled to obtain reliable ZTD as well as the PWV (Pacione and Vespe, 2003; Jin et al., 2008).

In this study the effect of ocean tides on GNSS ZTD and PWV are investigated with the usage of different ocean tide models in Turkey near the Mediterranean Sea, where the effects are as strong as near the oceans (Dach and Dietrich, 2000; Dragert et al., 2000; Hatanaka et al., 2001). In Section 2, data processing and methods are shown. Some results are presented in Section 3, including the effects on GNSS-estimated ZTD and Precipitable Water Vapour (PWV) with different OTL models in GNSS data processing. Finally, conclusions and suggestions are given.

\section{DATA PROCESSING AND METHODS}

In this study the GAMIT/GLOBK software (Herring et al., 2010), has been used to estimate the ZTD and other parameters with the constrained batch last squares inversion procedure. 
Orbit ephemeris are obtained from final International GNSS service (IGS)'s solution. By parameterizing the ZTD as stochastic variation of the Saastamoinen model, a piecewise linear interpolation between solution epochs is done (Saastamoinen, 1972). Additionally, a priori constraint of varying degrees of uncertainty is allowed.

In order to investigate various effects on GNSS ZTD and PWV estimates, different processing strategies are used, including different ocean tide models like, (1) FES2004 that is the product of assimilation of the altimetric data of TOPEX/POSEIDON and the data of a global tide gauge network, (2) NAO99b from a barotropic hydrodynamic model, (3) CSR4.0 obtained from TOPEX/Poseidon altimetry with the model FES94.1 as the reference model and (4) GOT00 that is again long wavelength adjustments of FES94.1 using TOPEX/Poseidon data at 0.5 by 0.5 degree grid. Full list of processing strategies are shown below in Table 1 .

\begin{tabular}{|c|c|c|}
\hline Strategy & Ocean Tide & Atm. Tide \\
\hline 1 & FES2004 & Yes \\
\hline 2 & NAO99b & Yes \\
\hline 3 & CSR4.0 & Yes \\
\hline 4 & GOT00 & Yes \\
\hline 5 & - & Yes \\
\hline
\end{tabular}

Table 1. Processing Strategies

For mapping function, in this study only the new Vienna Mapping Function (VMF1) has been used. Boehm and Schuh (2006) have stated that the coefficients of the VMF are derived by ray-tracing through actual meteorological data (the ECMWF global data) rather than using best-fitting values to radiosonde data (as per the NMF) or just some atmospheric parameters (such as the IMF).

Here GNSS data from Jan. $1^{\text {st }}$ to Dec. $31^{\text {st }}$ of 2014 are processed with GNSS network in Figure 1, including IGS sites (ZECK, SOFI, ORID, ISTA, ANKR and NICO) along with 4 radiosonde stations with co-located GNSS stations are used in Ankara, Istanbul, Adana, and Diyarbakir from Turkey, which belong to Turkish CORS Network called TUSAGA-Active (Figure 1) and Bulent Ecevit University. Also the IERS (International Earth Rotation Service) solid Earth tide and pole tide model, and a $10^{\circ}$ elevation cut-off angle are used in data processing.

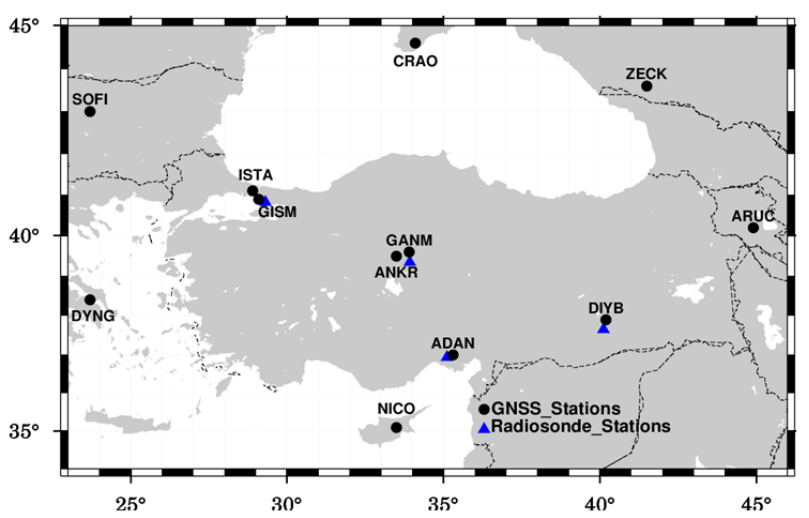

Figure 1. Co-located radiosonde and GNSS stations

Radiosonde observations are obtained from University of Wyoming Department of Atmospheric Science's web site. The coordinates of the stations are computed by processing 7 days of observations of the prior GPS week (Gurbuz et al., 2015). Then, these coordinates were fixed, and the wet tropospheric component delays are estimated every hour using ZTD, which can be split into hydrostatic (ZHD) and wet (ZWD) component of the delay (Rózsa et al., 2007). ZHD with approximately $90 \%$ of ZTD can be computed as follows (Davis et al., 1985):

$$
Z T D=Z H D+Z W D
$$

where

$$
Z H D=\frac{2,2768+0,0005}{1-0,00266 * \cos (2 \varphi)-0,00028 * \mathrm{~h}} * p
$$

where $\varphi=$ the latitude,

$\mathrm{h}=$ the height $(\mathrm{km})$ above the geoid,

$\mathrm{p}=$ the atmospheric pressure $(\mathrm{hPa})$ at the antenna height.

As can be seen at Eq. (2), GNSS-estimated ZHD values are directly related to the atmospheric pressure and the height $(\mathrm{km})$ above the geoid. At first, the hydrostatic part of the troposphere was calculated from the GPT (Global Pressure and Temperature), which is the GAMIT default. The GPT model is a global spherical harmonic fit (degree and order nine) to three years of gridded monthly Numerical Weather Model (NWM) pressure and temperature data to annual variations. So it accounts for major regional and seasonal scale variations only (Kouba, 2009). Input parameters of GPT are the station coordinates and the day of the year, thus also allowing one to model the annual variations of the parameters (Boehm et al., 2007). But results are not accurate enough. Therefore the real hourly meteorological parameters, which are obtained from Turkish met-office, rinex $\mathrm{m}$ files are generated and used. PWV values are computed with Sh_Met_Util by Bevis Tm model. Bevis model is based on the mean temperature of the water vapour and estimates the PWV as a function of the surface temperature formula as follows (Bevis et al., 1994):

$$
P W V=\prod * Z W D
$$

where

$$
\prod=\frac{10^{6}}{\rho \mathrm{R}_{v}\left[\left(\mathrm{k}_{3} / T_{m}+k_{2}^{\prime}\right)\right]}
$$

where $\rho=$ density of liquid water

$\mathrm{R}_{\mathrm{v}}=$ the specific gas constant for water vapour

$\mathrm{k}^{3}, \mathrm{k}_{2}^{\prime}=$ physical constants

$T_{m}=$ the mean temperature of the atmosphere, which can be computed from surface temperature as $T_{m}=70,2+0,72 * \mathrm{~T}_{\mathrm{s}}$ (Bevis et al., 1992).

\section{RESULTS}

In order to know the influence of the tide models on the total zenith delay and precipitable water vapour, five different GNSS solutions were performed. The ocean tide model FES2004 that is the product of assimilation of the altimetric data of ERS2, TOPEX/POSEIDON and the data of a global tide gauge network, gave the most accurate results when compared to radiosonde with $\pm 1.99 \mathrm{~mm}$ in $\mathrm{PWV}$ at stations near the coastline. Most effected GNSS station is ADAN with $\pm 1.99 \mathrm{~mm}$ in PWV (Figure 2). It is located in Adana city at the Mediterranean Sea coast (Figure 3). The results obtained from the FES2004 OTL model (strategy 1) are the most accurate with the smallest standard deviation at every GNSS stations. 


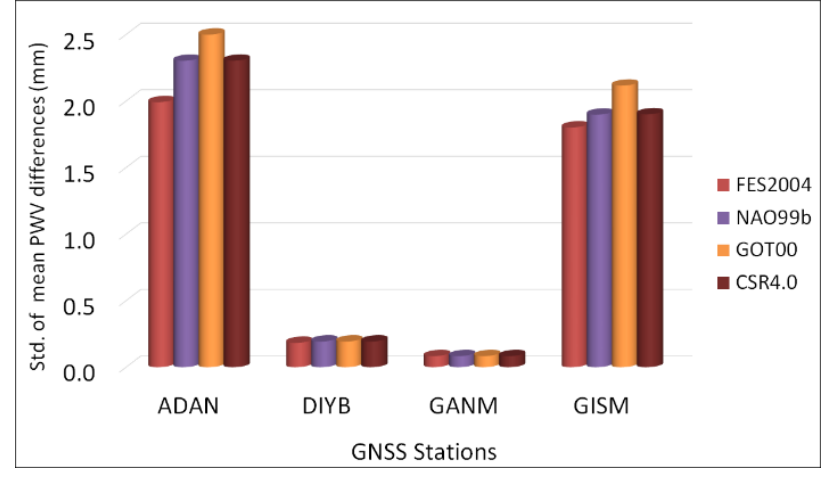

Figure 2. Standard deviation of mean differences between strategies using different Ocean Tide models and without OTL strategy.

As an example at DIYB station, which is located Diyarbakir, GNNS-estimated PWV values has a good agreement with radiosonde PWV values (Figure 4). However, the GANM station, which is located in Ankara city, has lower standard deviations compared with ADAN station.

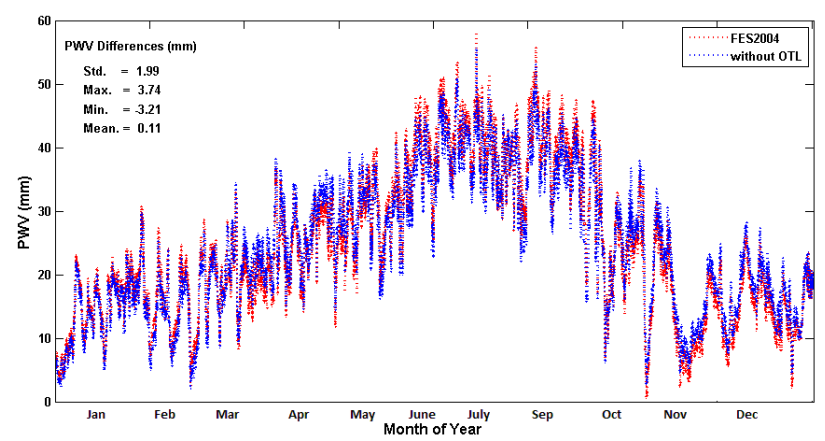

Figure 3. GNSS-estimated PWV time series at ADAN station

Also GISM station in Istanbul city has subjected to both Black Sea and Sea of Marmara ocean tide effects, the impact on PWV values (Figure 5) reaches 1-2 millimeters (Gurbuz et al., 2015). While GANM station, which is located in Ankara city, has no such effect since it is located in the middle of Turkey inland (Figure 6 and Figure 7).

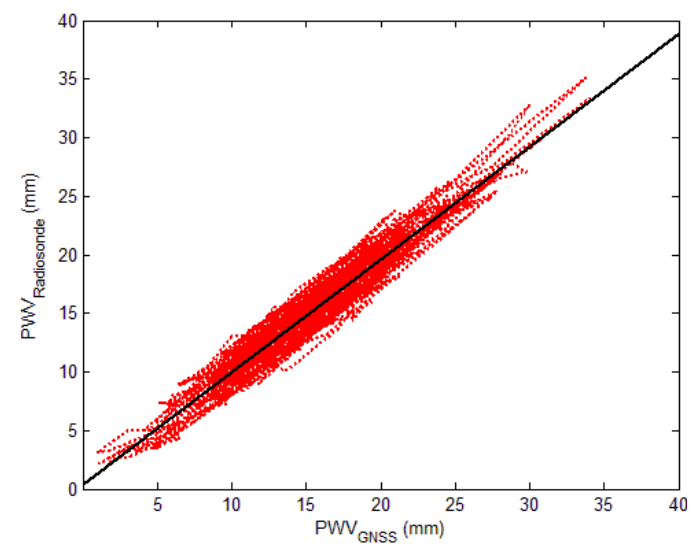

Figure 4. Correlation of GNSS-estimated PWV and radiosonde results at DIYB station

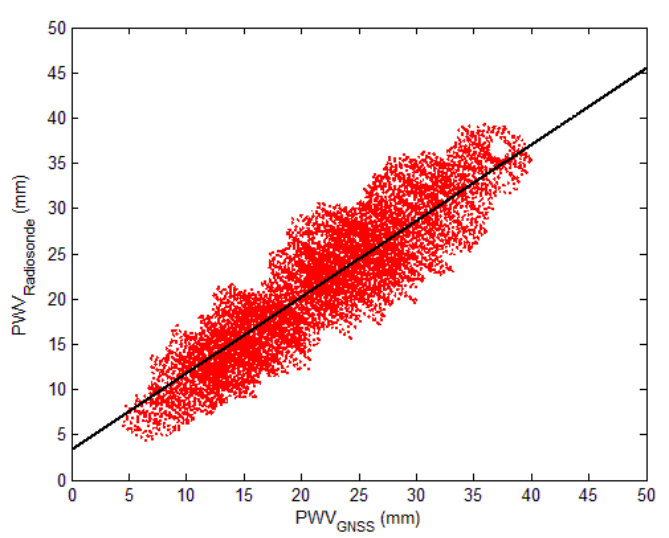

Figure 5. Correlation of GNSS-estimated PWV and radiosonde results at GISM station

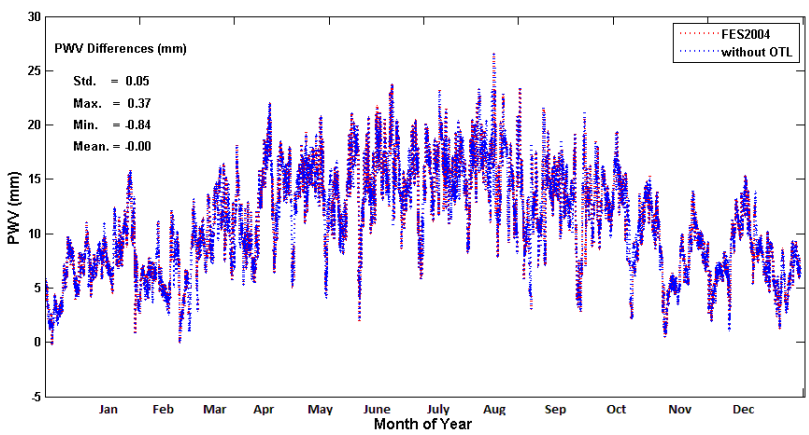

Figure 6. GNSS-estimated PWV time series at DIYB station

As can be seen in Figure 6 and Figure 7, the standard deviations between two different solutions, has sub-millimeter level agreement on PWV and millimeter level in ZTD. This is also similar or other inland located stations like GANM.

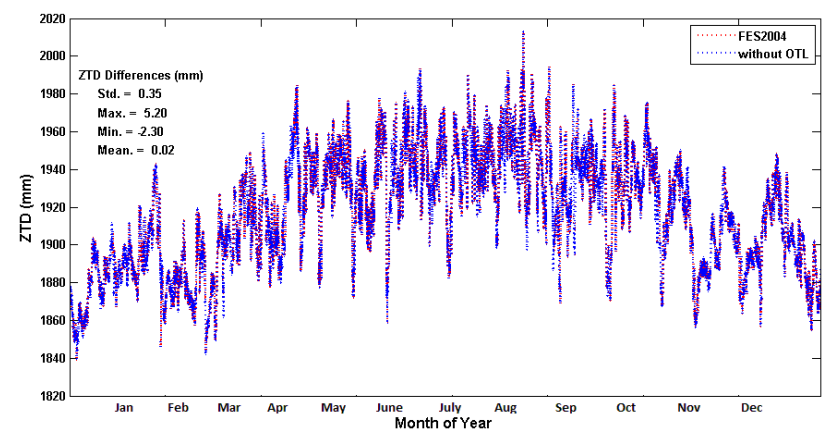

Figure 7. GNSS-estimated ZTD time series at DIYB station

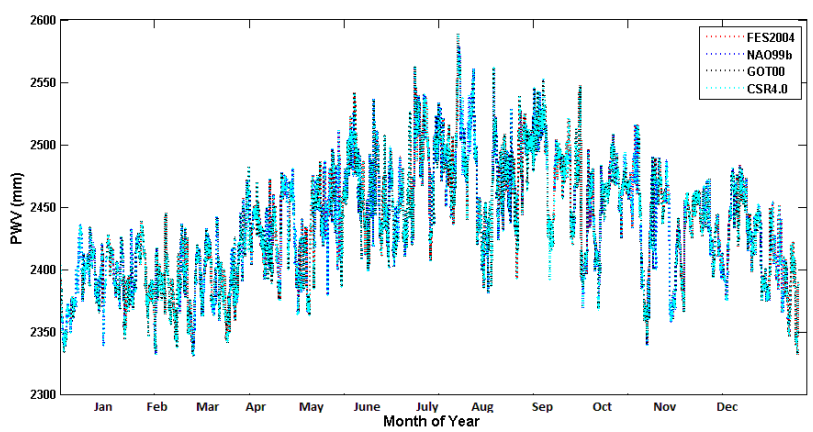

Figure 8. GNSS-estimated PWV at GANM station with 4 different tide models 
Similar to Wei et al., (2012) statement, no apparent difference between FES2004, GOT00, NAO99b and CSR4.0 solutions, has been seen at inland GNSS station like GANM, and DIYB (Figure 8). However, at stations like ADAN, GISM, which are near coastline, this situation is different.

\section{CONCLUSION}

The effects of OTL models on GNSS-estimated ZTD and PWV are investigated and compared with radiosonde PWV at 4 colocated stations in Turkey using GNSS data from Jan. $1^{\text {st }}$ to Dec. $31^{\text {st }}$ of 2014. Using different OTL models (FES2004, NAO99b, CSR4.0 and GOT00) in data processing, the standard deviation of ZTD differences is always better than those without OTL model at the stations near the coastline of Turkey. However, for stations near coastline, there are apparent differences between different OTL models.

The ocean tide model FES2004 that is the product of assimilation of the altimetric data of TOPEX/POSEIDON and the data of a global tide gauge network, gave the most accurate results when compared to radiosonde with $\pm 1.99 \mathrm{~mm}$ in PWV at stations near coastline. However, at inland GNSS stations, ocean tide models have less effects on GNSS-estimated ZTD and PWV, e.g., with $\pm 1.0 \mathrm{~mm}$ in ZTD and $\pm 0.1 \mathrm{~mm}$ in PWV. Therefore, the tide models still should be used for GNSS stations near the sea. Therefore, it is important to use ocean tide models properly when estimating ZTD and PWV parameters from GNSS measurements for meteorological applications.

\section{ACKNOWLEDGEMENTS}

Authors thank to IGS for providing the highly precise GNSS observation data and products. This work was supported by the TUBITAK-CAYDAG Project number 112Y350.

\section{REFERENCES}

Baker T. F., Curtis D. J., Dodson A. H., 1995. Ocean tide loading and GPS, GPS World 6 (3): 54-59.

Bevis, M., Businger, S., Herring, T. A., Rocken, C., Anthes, R., Ware, R., 1992. GPS meteorology: remote sensing of atmospheric water vapour using the global positioning system. J Geophys Res 97(D14):15787-15801.

Bevis, M., Chiswell, S., Hering, T. A., Anthes, R., Rocken, C., Ware, R., 1994. GPS meteorology: mapping zenith wet delays onto precipitable water. J Appl Meteorol 33: 379-386.

Boehm, J., Werl, B., and Schuh, H., 2006. Troposphere mapping functions for GPS and very long baseline interferometry from European Center for Medium-Range Weather Forecasts operational analysis data. J Geophys Res 111:B02406. Doi: 10.129/2005JB003629.

Boehm J, Niell, A. E., Tregoning, P., Schuh, H., 2007. Global mapping function (GMF): a new empirical mapping function based on data from numerical weather model data. Geophys ResLett 33:L07304. Doi: 10.1029/2005GL025546.

Dach, R., and R. Dietrich., 2000. Influence of ocean loading effect on GPS derived precipitable water vapour. Geophys. Res. Lett., 27, 2953-2956.
Davis, J. L., T. A. Herring, I. I. Shapiro, A. E. E. Rogers, and G. Elgered, 1985. Atmospheric Modelling Errors on Estimates of Baseline Length, Radio Science 20, 1593-1607.

Dragert, H., T. S. James, and A. Lambert, 2000. Ocean loading corrections for continuous GPS: A case study at the Canadian coast-al site Holberg Geophys. Res. Lett., 27, 2045-2048.

Duan J, Bevis M, Fang P, Bock Y, Chiswell S, Businger S, Rocken C, Solheim F, van Hove T, Ware R, McClusky S, Herring T. A., King R. W., 1996. GPS meteorology: direct estimation of the value of precipitable water. J Appl Meteorol 35(6): 830-838.

Gurbuz, G., S.G. Jin, and C. Mekik 2015. Sensing Precipitable Water Vapour (PWV) using GPS in Turkey: Validation and Variations, in S. Jin (Ed.), Satellite Positioning: Methods, Models and Applications, InTech-Publisher, Rijeka, Croatia, ISBN: 978-953-51-1738-4, pp.117-129.

Hatanaka, Y., A. Sengoku, T. Sato, J. M. Johnson, C. Rocken, and C. Meertens, 2001. Detection of tidal loading signal from GPS permanent array of GSI Japan.J. Geod. Soc. Japan, 47,187-192.

Herring, T.A., King, R.W., McClusky, S.C., 2010. GAMIT Reference Manual Reference Manual GPS Analysis at MIT. Department of Earth, Atmospheric, and Planetary Sciences Institute of Technology, Massachusetts.

Jin, S.G., Y. Wu, R. Heinkelmann, and J. Park, 2008. Diurnal and semidiurnal atmospheric tides observed by co-located GPS and VLBI measurements, J. Atmos. Sol.-Terr. Phys., 70(10), 1366-1372, doi: 10.1016/j.jastp.2008.04.005..

Kouba, J., 2009. Testing of global pressure/temperature (GPT) model and global mapping function (GMF) in GPS analyses. J Geod (2009) 83 (3),, pp. 199-208, DOI: 10.1007/s00190-0080229-6

Pacione, R., Vespe, F., 2007. Comparative studies for the assessment of the quality of near-real time GPS-derived atmospheric parameters. J Atmos Ocean Technol 25: 701-714.

Ponte, R. M., and Ray, R. D., 2002. Atmospheric pressure corrections in geodesy and oceanography: A strategy for handling air tides, Geophysical Research Letters, VOL. 29, doi: 10.1029/2002GL016340, 2002.

Rózsa, Sz., Dombai, F., Németh, P., Ablonczy, D., 2007. Estimation of integrated water vapour from GPS observations (in Hungarian) Geomatikai Közlemények, 12(1), 187-196.

Saastamoinen, J., 1972. Atmospheric correction for the troposphere and stratosphere in radio ranging of satellites, In: The Use of Artificial Satellites for Geodesy in Geodesy, Geophys. Monogr. Session. vol. 15.

Scherneck, H. G., 1991. A parameterized solid tide model and ocean tide loading effects for global geodetic baseline measurements. Geophys. J. Int., 106,677-694.

Wei, H., S.G. Jin, and X. He, 2012. Effects and disturbances on GPS-derived zenith tropospheric delay during the CONT08 campaign, Adv. Space Res., 50(5), 632-641, doi: 10.1016/j.asr.2012.05.017. 